\title{
The Trend of Prevalence for Leptospira Specific Antibodies among the Acute Febrile Patients in Peru
}

Hua-Wei Chen ${ }^{1 *}$, Zhiwen Zhang ${ }^{1}$, Tatyana Belinskaya ${ }^{1}$, Maya Williams ${ }^{1}$, Wei-Mei Ching ${ }^{1}$, Carolina Guevara ${ }^{2}$, Helvio Astete ${ }^{2}$, Crystyan Siles ${ }^{2}$, Mark P Simons ${ }^{2}$ and Robert D Hontz ${ }^{2}$

${ }^{1}$ Naval Medical Research Center, Silver Spring, Maryland, USA

${ }^{2}$ U.S. Naval Medical Research Unit, No. 6., Lima, Peru

\begin{abstract}
Leptospirosis is endemic in Peru, posing a medical threat to US Forces military personnel currently deployed in Peru. There are no reports of leptospirosis available for Peru in recent years. This study is aimed to identify the trend of prevalence for Leptospira-specific antibodies among the acute febrile patients in Peru using serological assays. The hypothesis is that the presence of detectable Leptospira-specific antibodies in these acute febrile patients should suggest an active or recent Leptospira infection. Seven hundred and fifty samples (two hundred and fifty samples each for the year 2005, 2010 and 2015) were arbitrarily selected from individuals enrolled in an acute febrile illness surveillance study in Peru that were negative for malaria and arbovirus isolation. The overall positive for Leptospira-specific antibodies among those acute febrile patients which were negative for malaria and arbovirus isolation was $32 \%, 24 \%$ and $16 \%$ for years 2005,2010 and 2015 respectively. Although, there was a decreasing trend of prevalence for Leptospira-specific antibodies among acute febrile patients which were negative for malaria and arbovirus isolation during the past 10 years, the $16 \%$ prevalence Leptospira-specific antibodies in 2015 was still quite high, indicating the potential high level of risk due to Leptospira-infection.
\end{abstract}

Keywords: Leptospirosis; Prevalence; Acute febrile; Peru

\section{Introduction}

Leptospirosis is a zoonotic disease of global importance [1-3]. Pathogenic Leptospira species colonize the renal tubules of carrier animals such as dogs, rats and cattle [4]. These maintenance hosts typically remain clinically asymptomatic and shed leptospires into the environment through their urine. Transmission of leptospirosis in humans and non-maintenance host animals occurs incidentally by exposure to water or soil contaminated by the urine of infected animals or by direct contact with infected animals [5]. The annual incidence of leptospirosis is estimated to range from $0.1-1$ cases per 100,000 population in temperate climates to $10-100$ cases per 100,000 population in humid tropical climates [6]. Countries with the highest reported incidence are in the Caribbean, Latin America, the Indian subcontinent, Southeast Asia and Oceania [3,7-8]. Although leptospirosis is present on the South American continent, it is not designated as a notifiable infectious disease in most of those countries. There are no reports of leptospirosis available for Peru over recent years. But earlier studies showed endemicity of the disease in the Peruvian Amazon region $[9,10]$. Symptoms of leptospirosis are like a variety of other febrile illnesses prominent in the same geographic regions, including malaria and dengue. As is common among febrile diseases, many leptospirosis cases are clinically misdiagnosed as malaria or dengue without using laboratory methods, contributing to the underreporting of leptospirosis. Since leptospirosis is present in Peru it poses a medical threat to U. S. military personnel currently deployed in that region, as well as their dependents $[9,10]$.

\section{Literature Review}

The objective of this study was to determine the prevalence of Leptospira-specific antibodies over time among acute febrile patients in Peru using serological assays. The detection of Leptospira-specific antibodies in those patients suggests an active or recent leptospirosis infection. Seven hundred and fifty samples (two hundred and fifty samples each for the calendar year 2005, 2010 and 2015) were arbitrarily selected from individuals enrolled in an acute febrile illness surveillance study in Peru that were negative for malaria and arbovirus isolation. Since malaria and arbovirus infection are two leading causes of febrile illness in Peru, samples were tested first for those two diseases. As listed in Table 1, the study population consisted of 121 (48\%), 107 (43\%) and 135 (54\%) males for years 2005, 2010 and 2015 respectively. The age range of the patients was 4-82 years (median 22 years, IQR 17 years), 5-78 years (median 28 years, IQR 23 years) and 5-90 years (median 23 years, IQR 22 years) for years 2005, 2010 and 2015, respectively. Serum samples were tested at a dilution of 1:100 for IgG or IgM against Leptospira by ELISA using a mixture of four conserved recombinant antigens $[11,12]$. The serum samples with either IgG ELISA absorbance $>0.39$ (mean of 20 negative controls plus 2.3 SDs for $95 \%$ confidence level) or IgM ELISA absorbance $>0.59$ (mean of 20 negative controls plus 2.3 SDs for $95 \%$ confidence level) were considered as seropositive for Leptospiral-specific antibodies.

Using the mixture of recombinant antigens in ELISA $20(8 \%)$, $28(11 \%)$ and $11(4 \%)$ samples were IgM positive for year 2005,2010 and 2015, respectively (Table 2) and $69(28 \%), 44(18 \%)$ and $33(13 \%)$ samples were IgG positive for year 2005, 2010 and 2015 respectively (Table 2). Our data showed higher percentage of IgG positive and lower percentage of IgM positive for sera from acute febrile patients. These could be due to previous exposures of Leptospira infection in a highly endemic area. The overall positive of Leptospira-specific antibodies among those acute febrile patients which were negative for malaria and arbovirus isolation was $32 \%, 24 \%$ and $16 \%$ for years 2005,2010 and 2015 respectively (Tables 1 and 2). The prevalence of seropositive

*Corresponding author: Hua-Wei Chen, Naval Medical Research Center, Silver Spring, Maryland, USA, Tel: 301-319-3109; E-mail: huawei.chen2.ctr@mail.mil

Received July 12, 2018; Accepted August 02, 2018; Published August 10, 2018

Citation: Chen HW, Zhang Z, Belinskaya T, Williams M, Ching WM, et al. (2018) The Trend of Prevalence for Leptospira Specific Antibodies among the Acute Febrile Patients in Peru. J Med Microb Diagn 7: 280. doi:10.4172/2161-0703.1000280

Copyright: $\odot 2018$ Chen HW, et al. This is an open-access article distributed under the terms of the Creative Commons Attribution License, which permits unrestricted use, distribution, and reproduction in any medium, provided the original author and source are credited. 
Citation: Chen HW, Zhang Z, Belinskaya T, Williams M, Ching WM, et al. (2018) The Trend of Prevalence for Leptospira Specific Antibodies among the Acute Febrile Patients in Peru. J Med Microb Diagn 7: 280. doi:10.4172/2161-0703.1000280

Page 2 of 3

\begin{tabular}{|c|c|c|c|c|c|c|c|c|c|c|c|c|}
\hline \multirow{2}{*}{ Characteristic } & \multicolumn{4}{|c|}{2005} & \multicolumn{4}{|c|}{2010} & \multicolumn{4}{|c|}{2015} \\
\hline & NS $^{a}(\%)$ & $N P^{b}(\%)$ & $\mathrm{OR}^{\mathrm{c}}$ & $p$-value & NS (\%) & NP (\%) & OR & $p$-value & NS (\%) & NP (\%) & OR & $p$-value \\
\hline Total & 250 & $80(32)$ & -- & -- & 250 & $61(24)$ & -- & -- & 250 & $40(16)$ & -- & -- \\
\hline \multicolumn{13}{|c|}{ Sex } \\
\hline Male & $121(48)$ & $45(37)$ & 1.59 & 0.09 & $107(43)$ & $33(31)$ & 1.83 & 0.04 & $135(54)$ & $28(21)$ & 2.25 & 0.03 \\
\hline Female & $129(52)$ & $35(27)$ & $* *$ & -- & $143(57)$ & $28(20)$ & $* *$ & -- & $115(46)$ & $12(10)$ & $\star *$ & -- \\
\hline \multicolumn{13}{|c|}{ Age (years) } \\
\hline$<16$ & $73(29)$ & $18(25)$ & ** & -- & $35(14)$ & $6(17)$ & ** & -- & $53(21)$ & $7(13)$ & ** & -- \\
\hline $16-30$ & $104(42)$ & $30(29)$ & 1.24 & 0.54 & $94(38)$ & $24(26)$ & 1.66 & 0.32 & $104(42)$ & $9(9)$ & 0.62 & 0.38 \\
\hline $31-45$ & $46(18)$ & $19(41)$ & 2.15 & 0.06 & $70(28)$ & $20(29)$ & 1.93 & 0.21 & $49(20)$ & $11(22)$ & 1.9 & 0.23 \\
\hline$>45$ & $27(11)$ & $13(48)$ & 2.84 & 0.03 & $51(20)$ & $11(22)$ & 1.33 & 0.61 & $44(17)$ & $13(30)$ & 2.76 & 0.05 \\
\hline \multicolumn{13}{|c|}{ Province } \\
\hline Maynas & $218(87)$ & $73(33)$ & ** & -- & $186(74)$ & $50(27)$ & ** & -- & $241(96)$ & $36(15)$ & ** & -- \\
\hline Alto Amazonas & $22(9)$ & $6(27)$ & 0.74 & 0.56 & $55(22)$ & $10(18)$ & 0.6 & 0.19 & $1(0)$ & $1(100)$ & 16.9 & 0.09 \\
\hline Chanchamayo & $4(2)$ & $1(25)$ & 0.66 & 0.72 & $9(4)$ & $1(11)$ & 0.34 & 0.31 & $4(2)$ & $3(75)$ & 17.1 & 0.02 \\
\hline Piura & $6(2)$ & $0(0)$ & 0.15 & 0.2 & $0(0)$ & $0(0)$ & --- & -- & $4(2)$ & $0(0)$ & 0.63 & 0.75 \\
\hline
\end{tabular}

Table 1: Demographics and seropositive for leptospiral-specific antibodies of study population for year 2005, 2010 and 2015.

\begin{tabular}{|c|c|c|c|c|}
\hline \multirow{2}{*}{ Year } & \multicolumn{4}{|c|}{ No. (\%) positive against } \\
\hline & No. of sera & $\lg M$ & IgG & $\lg M+\lg G^{*}$ \\
\hline 2005 & 250 & $20(8)$ & $69(28)$ & $80(32)$ \\
\hline 2010 & 250 & $28(11)$ & $44(18)$ & $61(24)$ \\
\hline 2015 & 250 & $11(4)$ & $33(13)$ & $40(16)$ \\
\hline
\end{tabular}

Table 2: Antibody response against 1:1:1:1 mixture of rLipL32, rLipL41, rLigA-Rep, and rLigB-Rep in acute febrile patent sera for year 2005, 2010 , and 2015.

among male patients was $10 \sim 11 \%$ higher than female patients in all three years ( $\mathrm{p}$ value is $0.088,0.039$ and 0.026 for year 2005,2010 and 2015 respectively) (Table 1). The odds ratios of seropositive for Leptospira-specific antibodies among male to female patients were 1.59, 1.83 and 2.25 for years 2005, 2010 and 2015, respectively. In majority of the cases, the prevalence increased as patient's age increased except the oldest group in year 2010 and the youngest group in year 2015. The increased trend of prevalence and patient age was clearly observed as the odds ratios for age groups $16-30,31-45$ and older than 45 , to age group younger than 16 were 1.24, 2.15 and 2.84, respectively (Table 1). In all three years, the odds ratios of seropositive for age group 31-45 to age group younger than 16 were about 2. Patient samples were collected from four different provinces (Figure 1). Maynas and Alto Amazonas are in northeast Peru in the Amazon region, which has a wet tropical climate. Chanchamayo is in central Peru which has a periodically wet climate. Piura is in northwest Peru which has a desert climate. No seropositive were found in Piura but the sample numbers were too small (ten) to make any conclusion. No obvious seasonal changes in seroprevalence among those patients in Maynas province for all three years were observed (Figure 2). Since most of the samples were collected in Maynas, the decreasing trend of seroprevalence over the past 10 years may only represent this area.

Previously, Johnson et al., reported the seroprevalence among residents in Belen (an urban slum area of Iquitos, the capital city of Maynas province of approximately 380,000 inhabitants located in the Amazon Basin of Northeastern Peru) was $28 \%$ about 17 years ago [9]. Here, we found that about $33 \%$ of patients in Maynas province with acute undifferentiated fever, but negative for malaria and arbovirus isolation, were seropositive for Leptospira-specific antibodies in 2005. The relationship between prevalence and age also showed the same

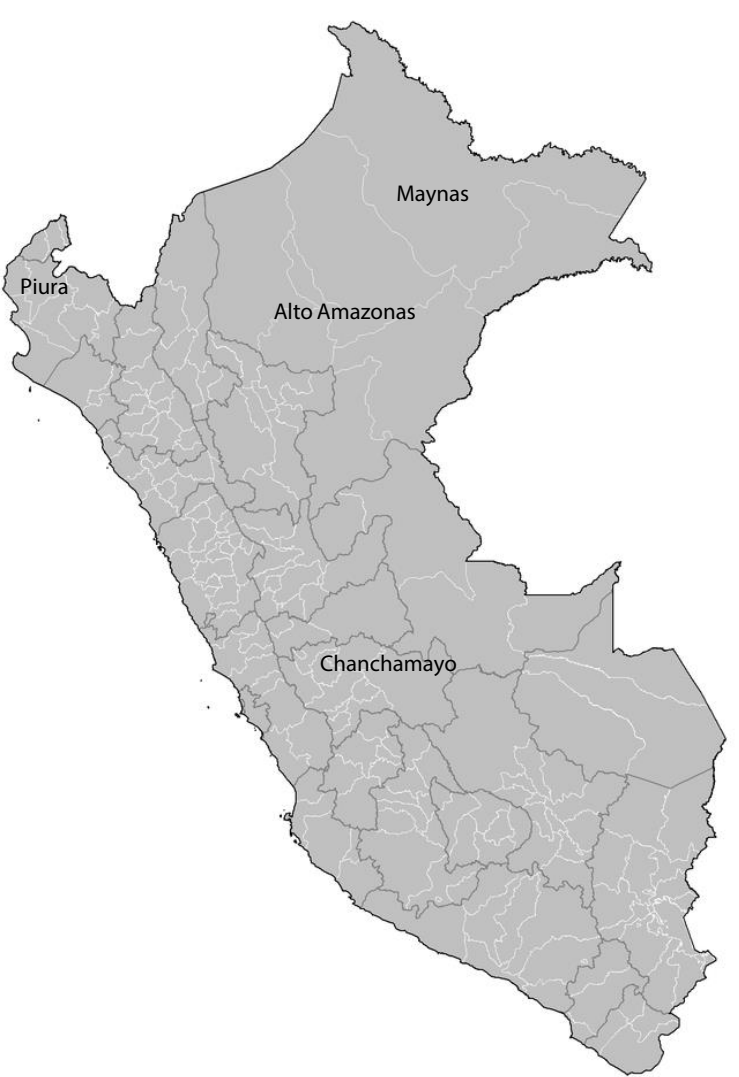

Figure 1: Collection sites in Peru 


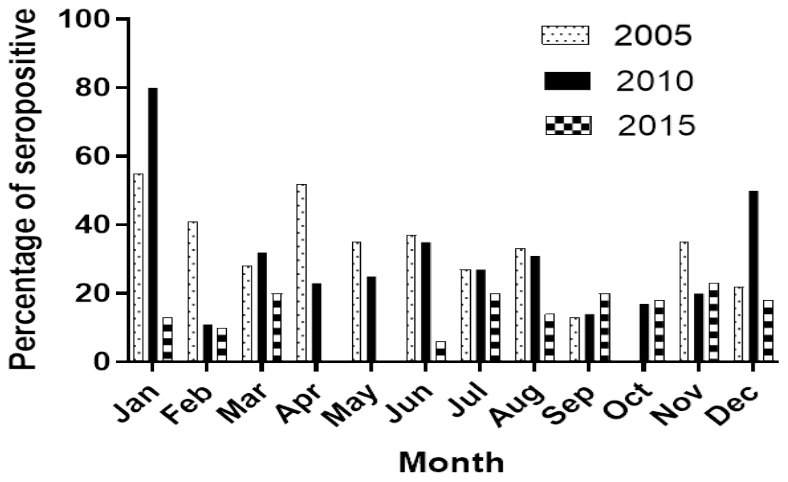

Figure 2: Monthly seroprevalence for Leptospira-specific antibodies among acute febrile patients which were negative for malaria and arbovirus isolation for years 2005, 2010, and 2015 in Maynas Province, Peru.

increasing trend as found in two other studies $[9,13]$. These data supported the hypothesis that continuous exposure to leptospires throughout life may result in an age-dependent increase in Leptospiral seropositivity. Additionally, we found higher prevalence rates for men than women. This is a well-recognized phenomenon for leptospirosis due to gender-specific occupational activities such as fishing, lumbering and farming by males among the study population [14-17].

\section{Discussion and Conclusion}

Although the same number of total samples was tested for each year in this study, the number of samples by month varied greatly in different years. Also, in different years, the samples from the same province were not all collected from the same clinical sites in the province. These are the limitations of our study. Both could be contributing factors in the observed difference of leptospirosis prevalence for each of the years studied. There was a decreasing trend of Leptospiral seroprevalence among acute febrile patients which were negative for malaria and arbovirus isolation during the past 10 years, the $16 \%$ prevalence of Leptospira-specific antibodies in 2015 was still quite high, indicating the high level of risk due to potential Leptospira-infection. Unfortunately, monthly rainfall and temperature data were not available for the years of collection to determine if this decrease was climate dependent. Detection of $16 \%$ to $32 \%$ of Leptospira-specific antibodies among these acute febrile patients should alert health-care providers to use a lower threshold for early antibiotic treatment of febrile illnesses in patients who have other signs and symptoms consistent with leptospirosis.

\section{Disclaimer}

The study protocol (PJT-16-16) was approved by the Naval Medical Research Center Institutional Review Board in compliance with all applicable Federal regulations governing the protection of human subjects. The views expressed herein are those of the authors and do not necessarily reflect the official policy or position of the Department of the Navy, Department of Defense, or the US Government. M.S., R.D.H., M.W. and W.-M.C. are employees of the US government. This work was prepared as part of their official duties.
Title 17 U.S.C. $\$ 105$ provides that 'Copyright protection under this title is not available for any work of the United States Government.' Title 17 U.S.C. $\$ 101$ defines a U.S. Government work as a work prepared by a military service member or employee of the U.S. Government as part of that person's official duties.

\section{Acknowledgement}

This study was supported by the Global Emerging Infections Surveillance section, at the Armed Forces Health Surveillance Branch. This work was supported by work unit number A0310. We thank DIRESA Loreto, Hospital La Merced (Junin), CS Pachitea (Piura), Dr. Stalin Vilcaromero, Michel Valerio and Victor Ocaña for their work in the field and for their help in collecting patient samples.

\section{References}

1. Levett PN (2001) Leptospirosis. Clin Microbiol Rev 14: 296-326.

2. Bharti AR, Nally JE, Ricaldi JN, matthias MA, Diaz MM, et al. (2003) Leptospirosis: A zoonotic disease of global importance. Lancet Infect Dis 3 757-771.

3. Pappas G, Papadimitriou P, Siozopoulou V, Christou L, Akritidis N (2008) The globalization of leptospirosis: Worldwide incidence trends. Int J Infect Dis 12: 351-357.

4. McBride AJ, Athanazio DA, Reis MG, Ko Al (2005) Leptospirosis. Curr Opin Infect Dis 18: 376-386.

5. Faine S, Alder B, Bolin C, Perolat P (1999) Clinical leptospirosis in humans. In Leptospira and leptospirosis $2^{\text {nd }}$ edition. Medi Sci, Melbourne.

6. WHO (2003) Human leptospirosis: Guidance for diagnosis, surveillance and control. Malta: World Health Organization.

7. Cruz LS, Vargas R, Lopes AA (2009) Leptospirosis: A worldwide resurgent zoonosis and important cause of acute renal failure and death in developing nations. Ethn Dis 2009 19: 37-41.

8. Victoriano AF, Smythe LD, Gloriani-Barzaga N, Cavinta LL, Kasai T, et al. (2009) Leptospirosis in the Asia Pacific region. BMC Infect Dis 9: 147.

9. Johnson MAS, Smith H, Joseph P, Gilman RH, Bautista CT, et al. (2004) Environmental exposure and leptospirosis, Peru. Emerg Infect Dis 10: 1016-1022.

10. Ganoza CA, Matthias MA, Collins-Richards D, Brouwer KC, Cunningham CB et al. (2006) Determining risk for severe leptospirosis by molecular analysis of environmental surface waters for pathogenic Leptospira. PLoS Med 3: e308.

11. Chen HW, Zhang Z, Halsey ES, Guevara C, Canal E, et al. (2013) Detection of Leptospira-specific antibodies using a recombinant antigen-based enzymelinked immunoassay. Am J Trop Med Hyg 89: 1088-1094.

12. Chen HW, Lukas H, Becker K, Weissenberger G, Halsey ES, et al. (2018) An improved enzyme-linked immunoassay for the detection of Leptospira-specific antibodies. Am J Trop Med Hyg 99: 266-274.

13. Sehgal SC, Vijayachari P, Murhekar MV, Sugunan AP (1999) Leptospira infection among primitive tribes of Andaman and Nicobar Islands. Epidemio Infect 122: 423-428.

14. Bovet $P$, Yersin C, Merien F, Davis CE, Perolat $P$ (1999) Factors associated with clinical leptospirosis: A population-based case-control study in the Seychelles (Indian ocean). Int J Epidemiol 28: 583-590.

15. Ashford DA, Kaiser RM, Spiegel RA, Perkins BA, Weyant RS, et al. (2000) Asymptomatic infection and risk factors for leptospirosis in Nicaragua. AM J Trop Med Hyg 63: 249-254.

16. Reis RB, Ribeiro GS, Felzemburgh RDM, Santana FS, Mohr S, et al. (2008) Impact of environment and social gradient on Leptospira infection in urban slums. PLoS Negl Trop Dis 2: e228.

17. Costa F, Hagan JE, Calcagno J, Kane M, Torgerson P, et al. (2015) Global morbidity and mortality of leptospirosis: A systematic review. PLoS Negl Trop Dis 9: e0003898. 